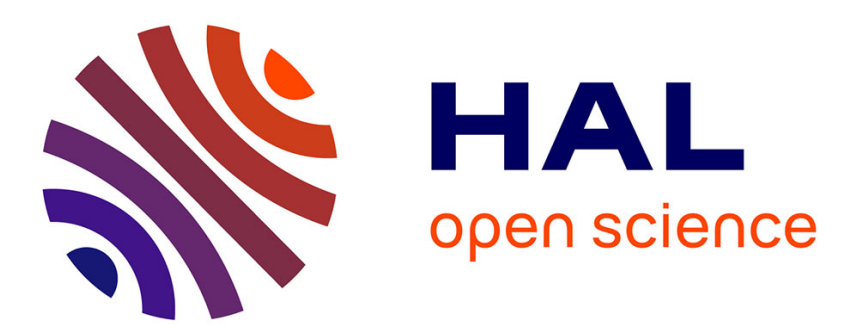

\title{
A predictive control for a matrix converter-fed permanent magnet synchronous machine
}

Florent Morel, Jean-Marie Rétif, Xuefang Lin-Shi, Bruno Allard, Pascal Bevilacqua

\section{- To cite this version:}

Florent Morel, Jean-Marie Rétif, Xuefang Lin-Shi, Bruno Allard, Pascal Bevilacqua. A predictive control for a matrix converter-fed permanent magnet synchronous machine. IEEE PESC, Jun 2008, Rhodes, Greece. pp.15 - 21, 10.1109/PESC.2008.4591889 . hal-00369416

\section{HAL Id: hal-00369416 https://hal.science/hal-00369416}

Submitted on 3 Jun 2009

HAL is a multi-disciplinary open access archive for the deposit and dissemination of scientific research documents, whether they are published or not. The documents may come from teaching and research institutions in France or abroad, or from public or private research centers.
L'archive ouverte pluridisciplinaire HAL, est destinée au dépôt et à la diffusion de documents scientifiques de niveau recherche, publiés ou non, émanant des établissements d'enseignement et de recherche français ou étrangers, des laboratoires publics ou privés. 


\title{
A Predictive Control for a Matrix Converter-Fed Permanent Magnet Synchronous Machine
}

\author{
Florent Morel, Jean-Marie Rétif, Xuefang Lin-Shi, Bruno Allard, Pascal Bevilacqua \\ AMPERE — INSA de Lyon \\ Bâtiment Léonard de Vinci \\ 21 avenue Jean Capelle \\ 69621 Villeurbanne Cedex \\ France \\ Email: florent.morel@insa-lyon.fr \\ Telephone: +33472438238 - Fax: +33472438530
}

\begin{abstract}
Many research efforts have been dedicated to matrix converters for several years. As major technological issues are now solved, this structure will widespread in industrial applications, in particular with $\mathrm{AC}$ motors. Current control is a key issue for AC motor drives, so many control schemes have been proposed. Some of them proposed at first for inverters, were applied to matrix converters. Among algorithms used with inverters, predictive control shows very good performances. In this paper a new control scheme is proposed for a matrix converterfed permanent magnet synchronous machine. Literature about matrix converter technology and control and about predictive control for inverter-fed AC machines is reviewed. The proposed predictive control principle, the model of the whole machine converter and the cost-function are detailed. The method offers a trade-off between the quality of motor currents and input power factor. Finally experimental results are reported. The feasibility and the effectiveness of the proposed method is assessed.
\end{abstract}

\section{INTRODUCTION}

A matrix converter is a set of bidirectional switches that directly connects a $m$-phase voltage source to a $n$-phase current source [1]. Generally $m=n=3$, the voltage source is the supply and the current source is an AC machine. In this case, a matrix converter is an array of nine bidirectional switches arranged in a way that any input phase (phase of the voltage source) can be connected to any output phase (phase of the AC machine) (Fig. 1).

This structure is still not common in industry applications but it presents some attractive features. Firstly output voltage amplitude and frequency can be controlled and the input power factor can be set. Secondly it is bidirectional in power.

Back-to-back converters present equivalent features but matrix converters are all-silicon converters. So it achieves ACAC conversion without any energy storage i.e. without a bulky and unreliable capacitor for DC energy storage. As a consequence matrix converters are a solution for applications with size [2] or reliability [3] constraints. Furthermore it has been shown [3] that the input filter that must be included has smaller inductances with a matrix converter than with a backto-back converter.

Maximum fundamental output voltage without low frequency distortion is limited to $86 \%$ of the maximum input voltage. This is a drawback compared to back-to-back converters but it is not a crucial issue if the designer can choose the load and the converter structure at the same time.

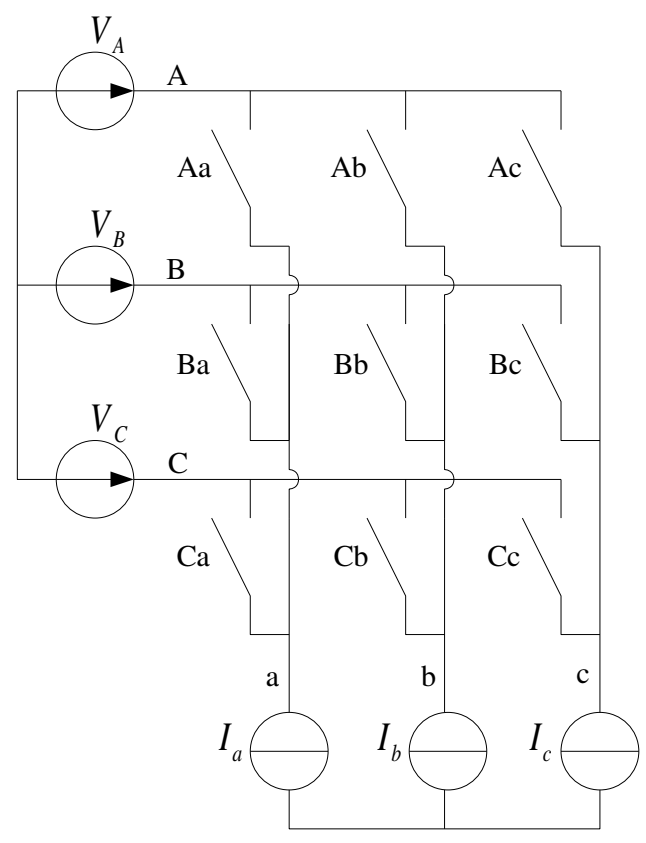

Fig. 1. Matrix Converter Structure

As a bidirectional controlled-switch does not exist it has to be made with discrete components. Classically it is done with two diodes and two IGBT but it can change in the near future. Indeed, new devices like reverse blocking IGBT [4] and silicon carbide JFET [5] are (or will be soon) available and their use in matrix converters is promising. Some studies are performed for module integration [6,7]. It shows the industrial interest for matrix converters and the bidirectional switch realisation will be no more an issue when these modules will be largely distributed.

As two input phases should never be short-circuited and any output phase should ever be opened, at any time, one and only one switch connected to an output phase must be closed. Due to its structure there is no free-wheeling path in a matrix converter. So commutation is an issue that can not be solved by dead times like with conventional inverters. Many semi-soft commutation sequences $[8,9]$ and control circuits [10] where proposed to solve this problem.

Two main technological issues of matrix converters (commutation and bidirectional controlled-switch realisation) are 
now solved so matrix converters can be considered as serious competitors to conventional converters in the near future. But there is still a peripheral problem to solve in order to prove the matrix structure superiority: when an inappropriate commutation sequence happens (due to current sign detection error for example) or in case of a hard shutdown, an overvoltage that can be dangerous for semi-conductor devices can happen. So an over-voltage protection system must be added. A diode-clamp protection circuit with a capacitor is often used [11] but this solution is expensive and bulky. Some solutions have been proposed to address this issue including varistors [12], active clamping [13] or shutdown commutation sequences [14]. Although it seems that none of these solution is widely used.

Research efforts about matrix converters does not deal only with power electronics: control is widely studied. Like for conventional motor drives, different control schemes applied to matrix converter-fed AC machines are reported in the literature. Most of them are adapted from control schemes originally designed for conventional motor drives. Vector control is such an example; it is widely used. This control needs a special algorithm to convert voltage references to power switch dutyratio values. There are several kinds of such algorithms.

The Venturini method [15] corresponds to a mathematical approach of this problem. It gives an analytical expression of duty-ratio values as functions of input voltages and desired output voltages. This method has two major limitations. First the knowledge of the load power factor is required to achieve the input power factor control at a value different of 1 . Second the maximum input-output voltage ratio decreases severely when input and output power factors differ.

Space Vector Modulation (SVM) is another way to compute duty-cycle values [16]. The output voltage frame is divided into six sectors. The sector including the desired output voltage vector is determined. The same determination is performed within the input current frame. Knowing desired input current sector and output voltage sector, a table gives four converter configurations to use. The computation time is reduced compared to Venturini method one [17] and it leads to an input power factor control independent from the load power factor. The maximum input-output voltage ratio is the same whatever the load power factor.

Direct Torque Control (DTC) is another control scheme designed for conventional motor drives which has been applied to matrix converters $[18,19]$. Torque and flux are controlled like with conventional DTC and the input power factor control is added. Experimental results are scarcely presented.

Some other control schemes use a virtual DC bus as an artifice [20,21]. It allows to separate the control issue into two independent control schemes (one for the input, the second for the output).

Recently predictive control was successively applied to conventional motor drives [22, 23]. Superior performances compared to vector control or DTC are reported [24]. During transient operation, rise times with predictive control are smaller than with vector control and equivalent than with DTC. During steady state operation oscillation currents are significantly reduced compared to DTC. These results lead to port it to other converter structures. In this paper a new predictive control is applied to a matrix converter-fed Permanent Magnet
Synchronous Machine (PMSM).

Firstly, used models for the PMSM, the matrix converter and the whole system are described. Then the cost function is explained and the control scheme steps are given. An experimental study is conducted in order to evaluate the influence of a tuning parameter in the cost function and in order to show the usefulness of matrix converter configurations that are not used by classical control schemes. Finally conclusions are given.

\section{Proposed Control Scheme}

In this paper, the presented predictive control consists in using a model of the whole converter - machine to predict the system behaviour after a computation period for each possible converter configuration. Then a cost function is used to determine the configuration that will be applied during the next computing period.

\section{A. Permanent Magnet Synchronous Machine Model}

The PMSM is classically modeled with state space equations in the $d q$ rotor frame (1) where $I_{d}, I_{q}$ and $V_{d}, V_{q}$ are stator currents and voltages expressed in the $d q$ frame, $R$ and $L$ are the stator winding resistor and inductance, $\omega$ is the rotor angular speed and $\phi$ is the flux produced by permanent magnets [25].

$$
\begin{aligned}
{\left[\begin{array}{c}
\dot{I}_{d}(t) \\
\dot{I}_{q}(t)
\end{array}\right]=} & {\left[\begin{array}{cc}
-\frac{R}{L} & \omega(t) \\
-\omega(t) & -\frac{R}{L}
\end{array}\right] \cdot\left[\begin{array}{c}
I_{d}(t) \\
I_{q}(t)
\end{array}\right] } \\
& +\left[\begin{array}{ccc}
\frac{1}{L} & 0 & 0 \\
0 & \frac{1}{L} & -\frac{\omega(t)}{L}
\end{array}\right] \cdot\left[\begin{array}{lll}
V_{d}(t) & V_{q}(t) & \phi
\end{array}\right]^{t}
\end{aligned}
$$

Model parameters $(R, L$ and $\phi)$ can be considered as constant and rotor electrical speed $(\omega)$ variations can be neglected for a short sampling period $\mathrm{T}$ of the algorithm. Then the following model can be found with a first order Euler integration.

$$
\begin{aligned}
{\left[\begin{array}{c}
I_{d}(k+1) \\
I_{q}(k+1)
\end{array}\right]=} & {\left[\begin{array}{cc}
1-\frac{R T}{L} & T \omega(k) \\
-T \omega(k) & 1-\frac{R T}{L}
\end{array}\right] \cdot\left[\begin{array}{l}
I_{d}(k) \\
I_{q}(k)
\end{array}\right] } \\
& +\left[\begin{array}{cc}
\frac{T}{L} & 0 \\
0 & \frac{T}{L}
\end{array}\right] \cdot\left[\begin{array}{c}
V_{d}(k) \\
V_{q}(k)
\end{array}\right]+\left[\begin{array}{c}
0 \\
-\frac{T \phi}{L} \omega(k)
\end{array}\right]
\end{aligned}
$$

This can be expressed as

$$
\underline{X}(k+1)=\boldsymbol{A}(k) \cdot \underline{X}(k)+\boldsymbol{B} \cdot\left[\begin{array}{c}
V_{d}(k) \\
V_{q}(k)
\end{array}\right]+\underline{\Phi}(k)
$$

where $\underline{X}(k)=\left[\begin{array}{ll}I_{d}(k) & I_{q}(k)\end{array}\right]^{t}, \boldsymbol{B}$ is a constant matrix, $\boldsymbol{A}$ and $\underline{\Phi}$ depend on rotation speed.

$V_{d}, V_{q}$ must be expressed as functions of converter switching states in order to obtain a model of the whole converter machine.

\section{B. Matrix Converter Model}

In the one hand $V_{d}, V_{q}$ can be expressed as functions of output voltages $\left[\begin{array}{llll}V_{a} & V_{b} & V_{c}\end{array}\right]^{t}$ using a rotation matrix

$$
\begin{aligned}
\boldsymbol{R}(\theta(k)) & =\left[\begin{array}{cc}
\cos (\theta(k)) & \sin (\theta(k)) \\
-\sin (\theta(k)) & \cos (\theta(k))
\end{array}\right] \\
{\left[\begin{array}{l}
V_{d}(k) \\
V_{q}(k)
\end{array}\right] } & =\boldsymbol{R}(\theta(k)) \cdot \underbrace{\sqrt{\frac{2}{3}} \cdot\left[\begin{array}{ccc}
1 & -\frac{1}{2} & -\frac{1}{2} \\
0 & \frac{\sqrt{3}}{2} & -\frac{\sqrt{3}}{2}
\end{array}\right]}_{\boldsymbol{C}} \cdot\left[\begin{array}{c}
V_{a}(k) \\
V_{b}(k) \\
V_{c}(k)
\end{array}\right]
\end{aligned}
$$

In the other hand output voltage can be expressed as function of input voltages with the following reasoning. 
Let define $\lambda \kappa(\lambda=A, B, C$ and $\kappa=a, b, c)$ as the switch between phases $\lambda$ and $\kappa$. Let define $u_{\lambda \kappa}$ as an integer that represent the switch state with the following convention: if $u_{\lambda \kappa}=0$ then the switch $\lambda \kappa$ is open; if $u_{\lambda \kappa}=1$ then the switch $\lambda \kappa$ is closed.

In a matrix converter, among the three switches connected to an output phase, one and only one switch can be closed. Indeed if more than one switch is closed, there is a shortcircuit of the voltage supply and if none is closed, there is no path for the output phase current. For example, for the phase $a$, this lead to

$$
u_{A a}+u_{B a}+u_{C a}=1
$$

and

$$
\begin{aligned}
& u_{A a}=1 \Rightarrow V_{a}=V_{A} \\
& u_{B a}=1 \Rightarrow V_{a}=V_{B} \\
& u_{C a}=1 \Rightarrow V_{a}=V_{C}
\end{aligned}
$$

then

$$
V_{a}=u_{A a} V_{A}+u_{B a} V_{B}+u_{C a} V_{C}
$$

As a result output voltages can be expressed as function of input voltages with (8).

$$
\left[\begin{array}{l}
V_{a}(k) \\
V_{b}(k) \\
V_{c}(k)
\end{array}\right]=\underbrace{\left[\begin{array}{lll}
u_{A a}(k) & u_{B a}(k) & u_{C a}(k) \\
u_{A b}(k) & u_{B b}(k) & u_{C b}(k) \\
u_{A c}(k) & u_{B c}(k) & u_{C c}(k)
\end{array}\right]}_{\boldsymbol{U}(k)} \cdot\left[\begin{array}{l}
V_{A}(k) \\
V_{B}(k) \\
V_{C}(k)
\end{array}\right]
$$

Eq.5 can be written for phase $b$ and $c$; as a result there are 27 admissible switching configurations for a three-phase to three-phase matrix converter. These converter configurations can be divided into three groups.

In the first one, each output phase is connected to a different input phase (e.g. $u_{A a}=u_{B b}=u_{C c}=1$ ). The corresponding output voltage vectors (in the $\alpha \beta$ stator frame) have a constant amplitude and a variable direction. There is six configurations in this group.

In the second group, each output phase is connected to the same input phase (e.g. $u_{A a}=u_{A b}=u_{A c}=1$ ) There is three configurations in this group. They lead to a null output voltage vector.

Finally the eighteen other configurations are in the third group. Two outputs are connected to the same input (e.g. $\left.u_{A a}=u_{A b}=u_{B c}=1\right)$. The corresponding output voltage vectors (in the $\alpha \beta$ stator frame) have a constant direction and a variable amplitude.

It is worth to note that, for each paper cited in reference, the six configurations from the first group are not considered. Predictive control can use these configurations.

\section{Model of the whole converter - machine}

Firstly with (2), (4) and (8), if output currents, input voltages $\left(\underline{V}_{i n}=\left[\begin{array}{lll}V_{A} & V_{B} & V_{c}\end{array}\right]\right)$, angular position and speed are measured, it is possible to predict every possible state vector after a sampling period $\underline{X}_{n}(k+1)(1 \leq n \leq 27)$ for each possible converter configuration $\boldsymbol{U}_{n}(9)$.

$$
\begin{aligned}
\underline{X}_{n}(k+1) & =\boldsymbol{A}(k) \cdot \underline{X}(k) \\
+ & \boldsymbol{B} \cdot \boldsymbol{R}(\theta(k)) \cdot \boldsymbol{C} \cdot \boldsymbol{U}_{n}(k) \cdot \underline{V}_{i n}(k)+\underline{\Phi}(k)
\end{aligned}
$$

Secondly as it is possible to achieve for currents a similar reasoning than the one used to demonstrate (8), it is also

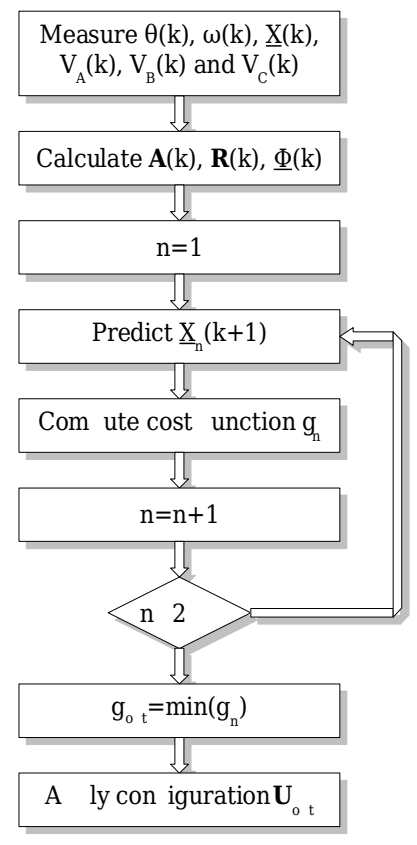

Fig. 2. Control scheme diagram

possible to predict input currents in a fixed frame $\mathcal{A B}$ after a sampling period for each converter configuration (10).

$$
\begin{aligned}
& {\left[\begin{array}{c}
I_{\mathcal{A}_{n}}(k+1) \\
I_{\mathcal{B}_{n}}(k+1)
\end{array}\right]=\frac{2}{3} \cdot\left[\begin{array}{ccc}
1 & -\frac{1}{2} & -\frac{1}{2} \\
0 & \frac{\sqrt{3}}{2} & -\frac{\sqrt{3}}{2}
\end{array}\right]} \\
& \cdot \boldsymbol{U}_{\boldsymbol{n}}{ }^{t}(k) \cdot\left[\begin{array}{cc}
1 & 0 \\
-\frac{1}{2} & \frac{\sqrt{3}}{2} \\
-\frac{1}{2} & -\frac{\sqrt{3}}{2}
\end{array}\right] \cdot \boldsymbol{R}(k)^{-1} \cdot\left[\begin{array}{l}
I_{d_{n}}(k+1) \\
I_{q_{n}}(k+1)
\end{array}\right]
\end{aligned}
$$

\section{Cost Function}

A cost function is used to determine which configuration must be applied. As the main goal of the control scheme is to control output currents, a first cost function that can be proposed is the sum of differences between the reference currents $I_{d, q}^{\#}$ and the predicted currents (11).

$$
g_{n}=\left|I_{d}^{\#}-I_{d_{n}}(k+1)\right|+\left|I_{q}^{\#}-I_{q_{n}}(k+1)\right|
$$

With this cost function, only output currents are controlled. However the matrix converter structure also allows to control input power factor. So input currents are computed with (10) in order to compute the angle between input current vector and input voltage vector if the configuration $n$ is applied $\left(\phi_{i_{n}}\right)$. Then a third term is added in (11) to take into account input power factor and in order to make it as close to unity as possible (12).

$g_{n}^{\prime}=\left|I_{d}^{\#}-I_{d_{n}}(k+1)\right|+\left|I_{q}^{\#}-I_{q_{n}}(k+1)\right|+c \cdot\left|\sin \left(\phi_{i_{n}}(k+1)\right)\right|$

In (12) $c$ is a weighting factor. Actually the instantaneous angle between input current vector and input voltage vector is used as a way to act on input power factor.

With $c$, it is possible to obtain a trade-off between output current control and input power factor controls.

\section{E. Control Scheme Steps}

Figure 2 depicts the whole algorithm. At each sampling period input voltages, stator currents and angular position 


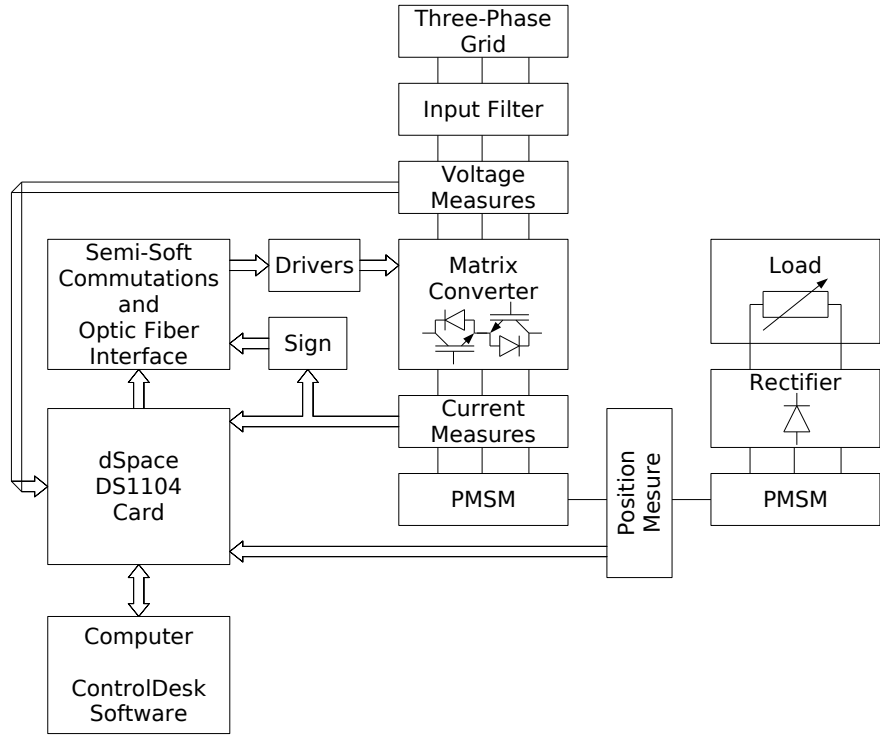

Fig. 3. Test-bench configuration

TABLE I

PARAMETERS OF THE PMSM

\begin{tabular}{crl}
\hline \hline Rated Torque & 5 & $\mathrm{Nm}$ \\
Rated Speed & 3000 & $\mathrm{rpm}$ \\
$R$ & 2.06 & $\Omega$ \\
$L$ & 9.15 & $\mathrm{mH}$ \\
$\phi$ & 290 & $\mathrm{mWb}$ \\
Number of pole pairs $(\mathrm{p})$ & 3 & \\
\hline \hline
\end{tabular}

are measured. Model components are then computed $(\boldsymbol{A}(k)$, $\underline{\Phi}(k) \ldots)$. State vector and input currents are predicted for the 27 appropriate converter configurations in order to compute a cost function. The converter configuration that minimize this cost function is applied for the duration of a sampling period.

\section{EXPERIMENTAL STUDY}

In addition to show the feasibility of the proposed scheme, experimental results are performed with the aim to show the influence of $c$ and the usefulness of first-group configurations.

\section{A. Hardware and Software}

The test bench (Fig. 3) is composed of a laboratory-scale matrix converter including 18 IGBT. Semi-soft commutations are achieved with a board including a FPGA. Two identical PMSM (see parameters in Tab. I) are used; the first one is fed by the matrix converter, the other one is used as a load torque generator. An incremental encoder with 4096 points is used. Input voltages $(400 \mathrm{~V}, 50 \mathrm{~Hz})$ and output currents are measured.

An input filter is inserted between the matrix converter and the grid. As this filter is not included in the used model, the control scheme does not deal with grid currents but with converter input currents. So in the sequel of this paper grid currents will not be considered.

The algorithm is implemented in C-language on a dSpace DS1104 controller board. This card provide a master processor: PowerPC $603 \mathrm{e}$ at $250 \mathrm{MHz}$ and and slave DSP TMS320 F240 at 20MHz. The shortest sampling period that can be obtained with the proposed control scheme and this computation unit is $158 \mu \mathrm{s}$. This is too large for a low power PMSM so $85 \mathrm{mH}$ inductances are added in series with the PMSM.
It is worth to note that these inductances emulate a higherpower machine. Actually they would be useless in the case of a high power machine (with smallest current dynamic) or if the computing duration was negligible compared to current rise time. In this regard the control scheme implementation using a FPGA [26] seems to be an interesting perspective since it could take advantage of the inherent parallelism of the algorithm (prediction of $\underline{X}_{n}(k+1) 27$ times).

The ControlDesk environment is used to perform data recording and reference value tuning.

\section{B. Experimental Conditions}

A reference state vector $\underline{X}^{\#}=\left[\begin{array}{ll}I_{d}^{\#} & I_{q}^{\#}\end{array}\right]^{t}$ has to be determined for the proposed control scheme. For a PMSM the electromagnetic torque is proportional to $I_{q}$, then the minimisation of the Joule power losses leads to fix the current $I_{d}$ to zero. Consequently, reference values are $I_{d}^{\#}=0 \mathrm{~A}$ and $I_{q}^{\#}$ proportional to the desired torque $T^{\#}\left(I_{q}^{\#}=\frac{T^{\#}}{p * \phi}\right)$.

During experiments $I_{q}^{\#}$ is is set to $5.75 \mathrm{~A}$ in order to obtain the rated torque. Transient operations are obtained by changing the $I_{q}^{\#}$ sign.

It is worth to note that the proposed control scheme is equivalent to a torque control. Indeed there is no speed loop. Generally torque controllers are used inside a speed loop. It is not the case in the presented experiments. Angular speed is not controlled, it is just an outcome of test bench mechanical parameters like inertia, frictions or load torque. During steady state operation this speed approximates 400rpm.

\section{Influence of the value of $c$}

Figures 4 to 8 illustrate the influence of $c$. At first $c$ is set to $0 \mathrm{~A}$; this is equivalent to only deal with output currents i.e. equivalent to not consider the instantaneous value of the input phase difference. The second value of $c$ used during experiments is $1 \mathrm{~A}$; this quite large value is chosen to show the influence of this parameter.

When $c$ is set to $0 \mathrm{~A}$, it can be seen that output phase currents (Fig. 4(a)) are very near to sinusoidal shapes but with a large value of $c$ these currents (Fig. 4(b)) are significantly affected. Similar comments can be done when considering output currents expressed in the $d q$ frame (Fig. 5) and output phase current spectra (Fig. 6). Indeed the larger the value of $c$ the worst the output currents quality : current oscillations are significantly larger when $c$ equals $1 \mathrm{~A}$. About transient operation it can be seen (Fig. 5) that, whatever the value of $c$, the rise time is very short (near $2.5 \mathrm{~ms}$ i.e. 15 sampling periods). Furthermore there is no overshoot and the static error is negligible.

During this transient operation angular speed grows from almost -400rpm to 400rpm with the shape of an exponential function with a time constant close to $17 \mathrm{~ms}$ (due to inertia, frictions... and not due to the presented control scheme). Then it can be seen that the control scheme features are independent from angular speed (Fig. 5).

Output current Spectra (Fig. 6) presents harmonics at low frequencies (at less that $500 \mathrm{~Hz}$ ) that are clearly larger when $c$ is not null.

Advantages of a large value of $c$ are clearly shown on figures 7 and 8. Input power factor ${ }^{1}$ is improved (Fig. 7) when

\footnotetext{
${ }^{1}$ Actually the instantaneous value of the cosine of the input phase difference
} 

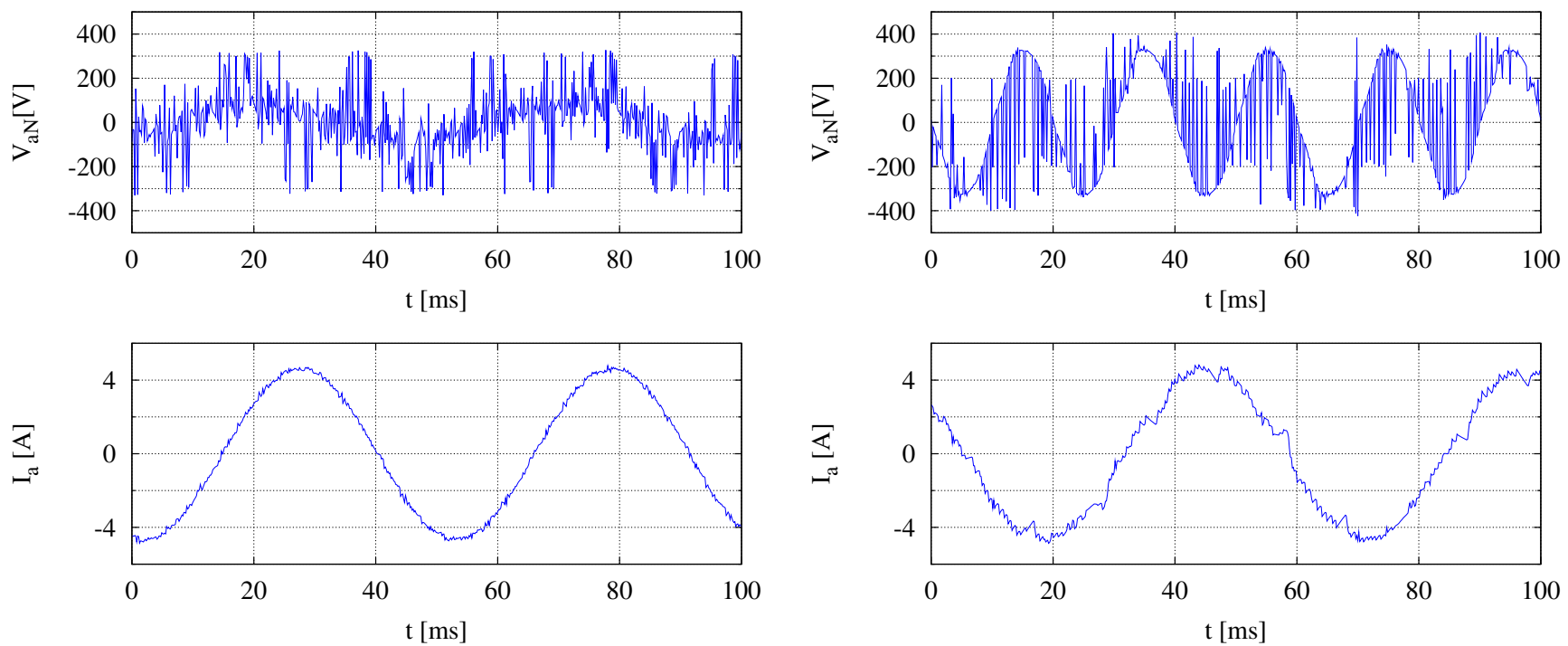

(a) $c=0 A^{-1}$

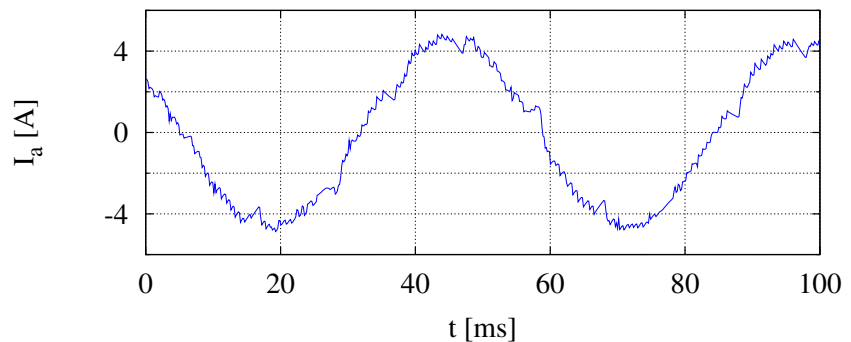

(b) $c=1 A^{-1}$

Fig. 4. Influence of $c$ on output voltage and output current

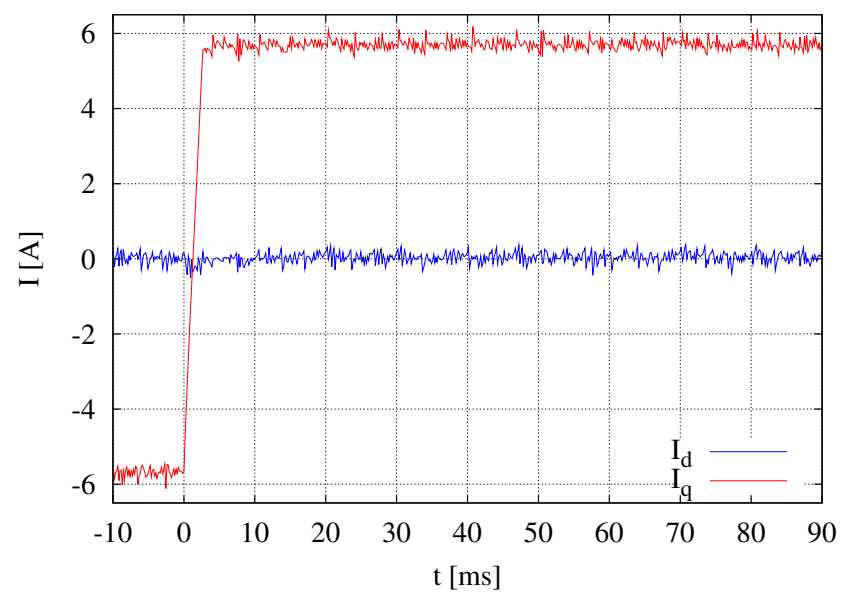

(a) $c=0 A^{-1}$

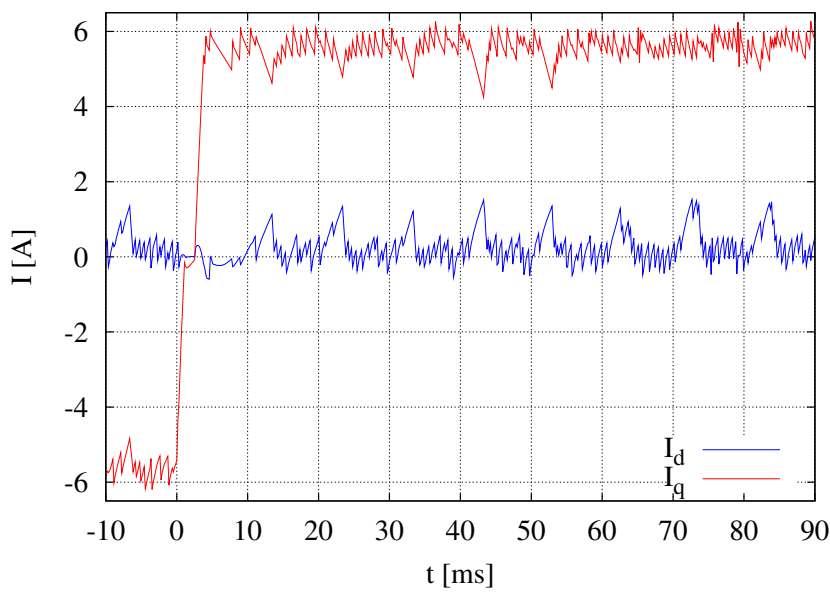

(b) $c=1 A^{-1}$

Fig. 5. Influence of $c$ on output currents in the $d q$ frame (transient operation)

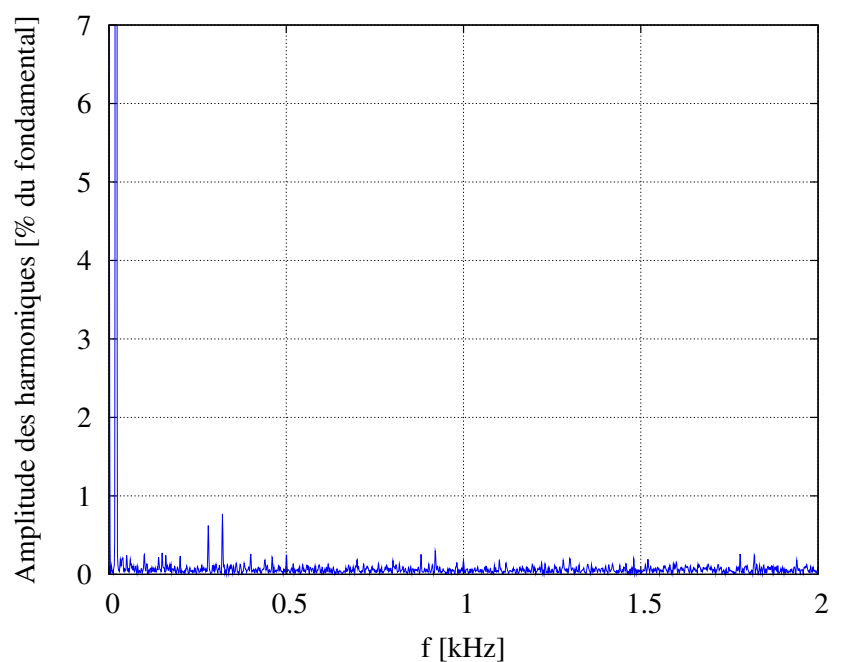

(a) $c=0 A^{-1}$

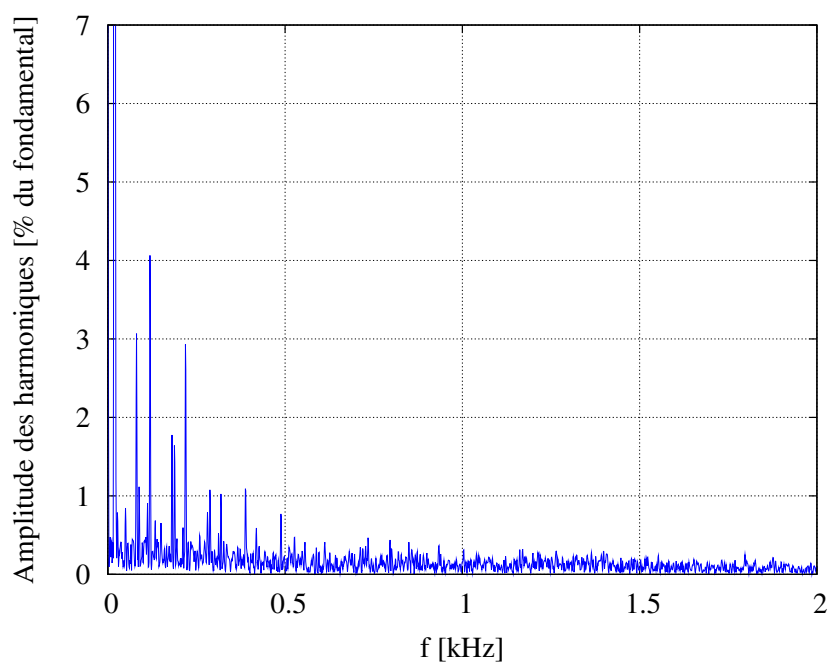

(b) $c=1 A^{-1}$

Fig. 6. Influence of $c$ on output spectrum 

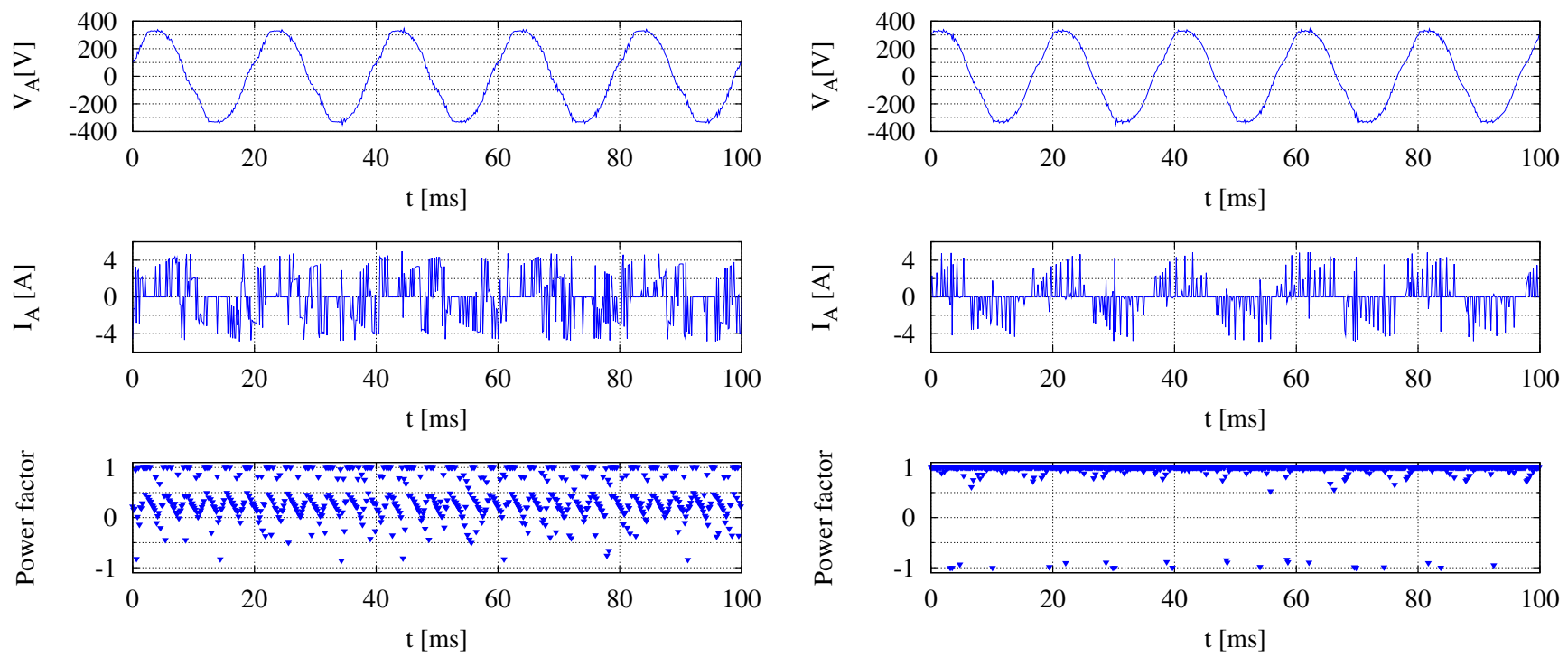

(a) $c=0 A^{-1}$

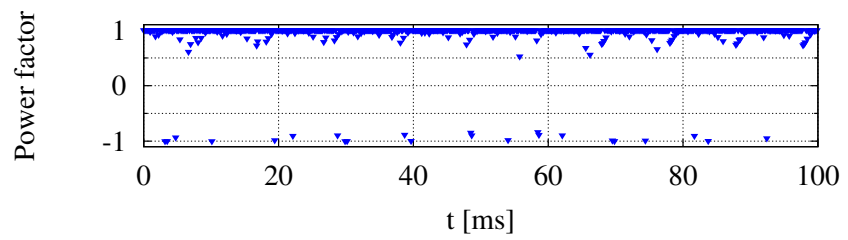

(b) $c=1 A^{-1}$

Fig. 7. Influence of $c$ on input current and instantaneous value of the cosine of the input phase difference

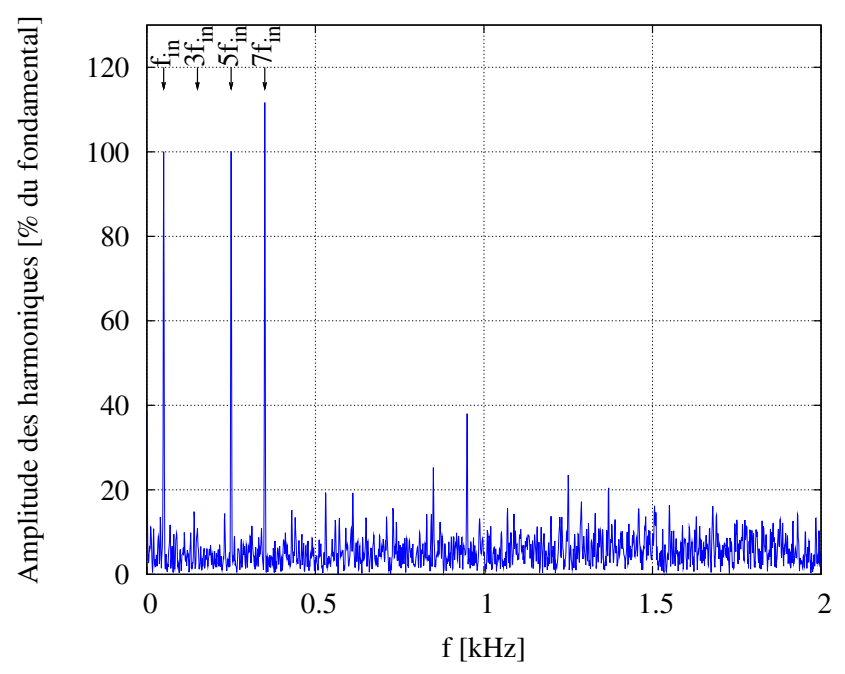

(a) $c=0 A^{-1}$

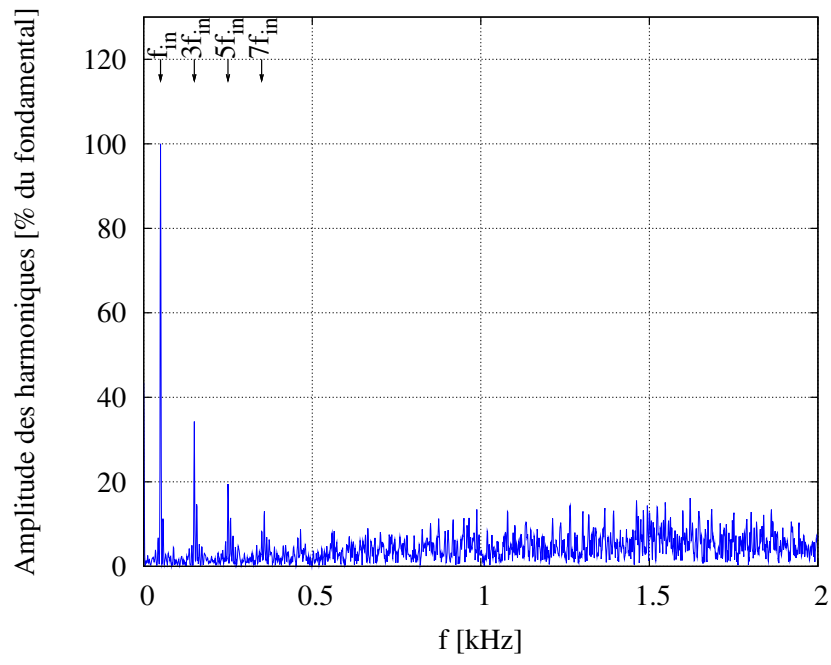

(b) $c=1 A^{-1}$

Fig. 8. Influence of $c$ on input spectrum

the value of $c$ is large. Indeed the mean value is 0.374 when $c$ is zero and 0.914 when $c$ equals $1 \mathrm{~A}$.

The input filter is not considered in this study and this explains the high harmonic content of input currents (Fig. 7). It is obvious that, with an well-designed input filter ${ }^{2}$, input currents are nearly sinusoidal. When $c$ equals $1 \mathrm{~A}$, a fundamental component in phase with the input voltage can be seen in input current (Fig. 7(b)) while it is not the case when $c$ is zero (Fig. 7(a). Thus the larger the value of $c$ the easier the input current filtering. This is confirmed by input current spectrum (Fig. 8). When the value of $c$ is large, low-frequency harmonics are reduced (particularly for orders 5 and 7).

\section{Usefulness of first-group configurations}

Similar experiments were performed without taking into account first-group configurations in order to show their usefulness (Fig. 9). It can be seen that output currents are affected:

\footnotetext{
${ }^{2}$ This design depends on control scheme performances thus on the value of $c$. This is a reason why input currents are not considered here.
}

the oscillation amplitude is increased (Fig. 9(a)) and there is a significantly higher level of low frequency harmonics in output currents (Fig. 9(b)). Furthermore there almost no difference in input current spectra ${ }^{3}$ (with or without first-group configurations).

\section{CONCLUSION}

A control scheme for a matrix converter-fed PMSM was presented and experimentally validated. It presents two characteristics: a weighting factor can be defined in the cost function and it can use converter configurations that are not taken into account by other control schemes.

The value of the weighting factor $c$ is very important. The larger $c$ the worst the output currents quality and the easier the input current filtering. Thus the control scheme designer must deal with this trade-off considering load and grid requirements.

\footnotetext{
${ }^{3}$ These spectra are not shown in this paper due to the lack of space
} 


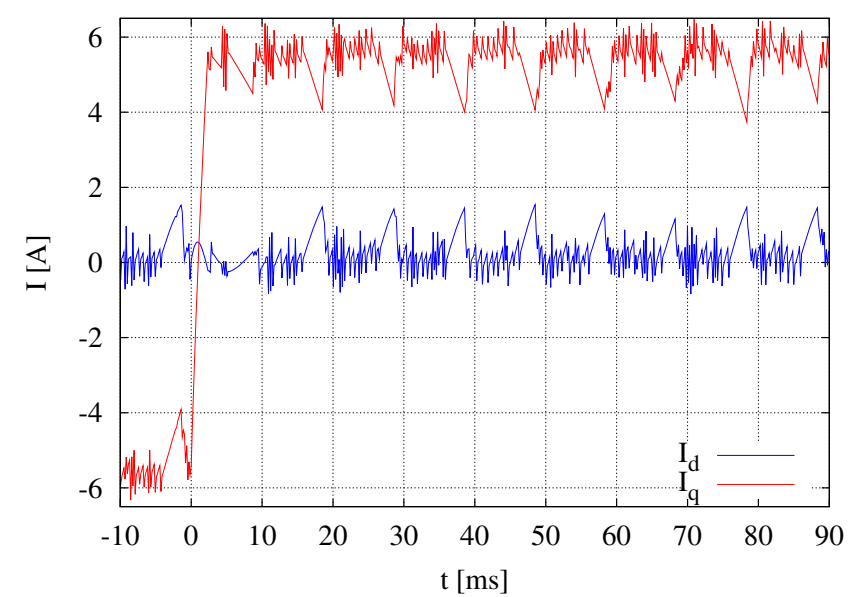

(a) State variables during transient operation (to compare with Fig. 5(b))

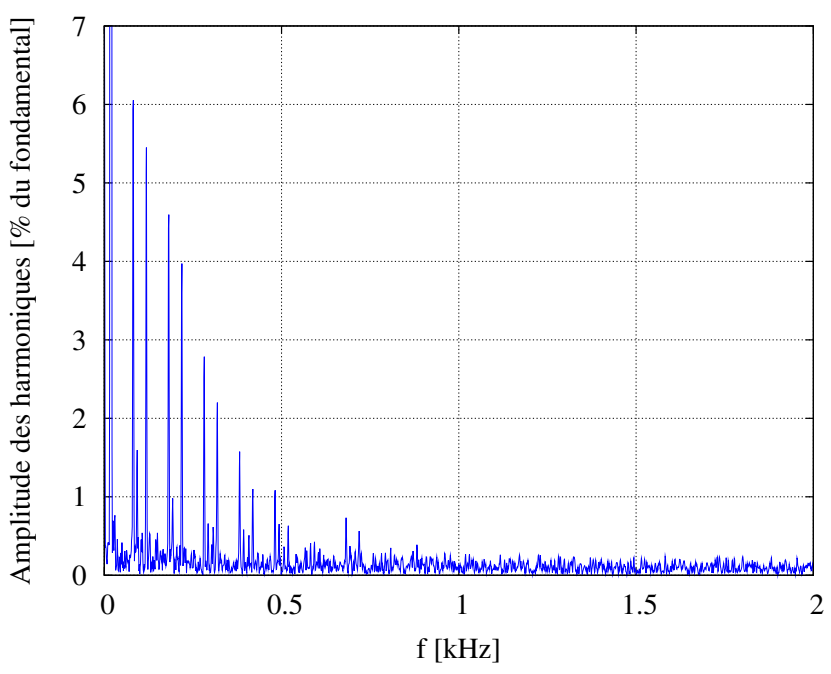

(b) Output spectrum (to compare with Fig. 6(b))

Fig. 9. Results when first-group configurations are not used (when $c=1 A$ )

The use of first-group configurations increases the amount of computations but leads to better output currents. This is an advantage over control schemes that use a pulse width modulation for example.

Further work will consist in including the input filter model in the model considered and to control grid currents together with output currents.

\section{REFERENCES}

[1] P. W. Wheeler, J. Rodriguez, J. C. Clare, L. Empringham, and A. Weinstein, "Matrix converters: a technology review," IEEE Trans. Ind. Electron., vol. 49, no. 2, pp. 276-288, Apr. 2002.

[2] P. W. Wheeler, J. C. Clare, M. Apap, L. Empringham, K. J. Bradley, S. Pickering, and D. Lampard, "A fully integrated $30 \mathrm{kw}$ motor drive using matrix converter technology," in Power Electronics and Applications, 2005 European Conference on, Sept. 11-14, 2005.

[3] M. Aten, G. Towers, C. Whitley, P. Wheeler, J. Clare, and K. Bradley, "Reliability comparison of matrix and other converter topologies," IEEE Trans. Aerosp. Electron. Syst., vol. 42, no. 3, pp. 867-875, July 2006.

[4] J. Itoh, I. Sato, A. Odaka, H. Ohguchi, H. Kodachi, and N. Eguchi, "A novel approach to practical matrix converter motor drive system with reverse blocking IGBT," IEEE Trans. Power Electron., vol. 20, no. 6, pp. 1356-1363, Nov. 2005.

[5] D. Domes and W. Hofman, "Sic jfet in contrast to high speed si igbt in matrix converter topology," 2007. PESC 07. 2007 IEEE 38th Annual Power Electronics Specialists Conference, pp. 54-60, 2007.
[6] M. Hornkamp, M. Loddenkötter, M. Münzer, O. Simon, and M. Bruckmann, "Economac the first all-in-one igbt module for matrix converters," http://www.scut-co.com/maindoc/techtrade/Pdevice/ eupec/documents/techsupport/ed_economac.pdf.

[7] K. Sun, D. Zhou, L. Huang, K. Matsuse, and K. Sasagawa, "A Novel Commutation Method of Matrix Converter Fed Induction Motor Drive Using RB-IGBT,' IEEE Trans. Ind. Applicat., vol. 43, no. 3, pp. 777786, May/June 2007.

[8] P. W. Wheeler, J. C. Clare, L. Empringham, M. Bland, and K. G. Kerris, "Matrix converters," IEEE Ind. Appl. Mag., vol. 10, no. 1, pp. 59-65, Jan./Feb. 2004.

[9] O. Simon, J. Mahlein, M. N. Muenzer, and M. Bruckmarm, "Modern solutions for industrial matrix-converter applications," IEEE Trans. Ind. Electron., vol. 49, no. 2, pp. 401-406, Apr. 2002.

[10] J. L. Galvez, X. Jorda, M. Vellvehi, J. Millan, M. A. Jose-Prieto, and J. Martin, "Intelligent bidirectional power switch module for matrix converter applications," in Power Electronics and Applications, 2007 European Conference on, Sept. 2-5, 2007, pp. 1-9.

[11] L. Empringham, L. de Lillo, P. W. Wheeler, and J. C. Clare, "Matrix Converter Protection for More Electric Aircraft Applications," in IEEE Industrial Electronics, IECON 2006 - 32nd Annual Conference on, Paris, France, Nov. 2006, pp. 2564-2568.

[12] J. Mahlein and M. Braun, "A matrix converter without diode clamped over-voltage protection," in Power Electronics and Motion Control Conference, 2000. Proceedings. IPEMC 2000. The Third International, vol. 2, Beijing, Aug. 15-18, 2000, pp. 817-822.

[13] J. Mahlein, M. Bruckmann, and M. Braun, "Passive protection strategy for a drive system with a matrix converter and an induction machine," IEEE Trans. Ind. Electron., vol. 49, no. 2, pp. 297-303, Apr. 2002.

[14] A. Schuster, "A matrix converter without reactive clamp elements for an induction motor drive system," in Power Electronics Specialists Conference, 1998. PESC 98 Record. 29th Annual IEEE, vol. 1, Fukuoka, May 17-22, 1998, pp. 714-720.

[15] A. Alesina and M. G. B. Venturini, "Analysis and design of optimumamplitude nine-switch direct AC-AC converters," IEEE Trans. Power Electron., vol. 4, no. 1, pp. 101-112, Jan. 1989.

[16] D. Casadei, G. Serra, A. Tani, and L. Zarri, "Matrix converter modulation strategies: a new general approach based on space-vector representation of the switch state," IEEE Trans. Ind. Electron., vol. 49, no. 2, pp. 370-381, Apr. 2002.

[17] L. Zhang, C. Watthanasarn, and W. Shepherd, "Analysis and comparison of control techniques for AC-AC matrix converters," IEE ProceedingsElectric Power Applications, vol. 145, pp. 284-294, July 1998.

[18] D. Casadei, G. Serra, and A. Tani, "The use of matrix converters in direct torque control of induction machines," IEEE Trans. Ind. Electron., vol. 48, no. 6, pp. 1057-1064, Dec. 2001.

[19] C. Ortega, A. Arias, J. Ballcells, C. Caruana, C. Spiteri, and J. Cilia, "The Use of Small Voltage Vectors of Matrix Converters in Direct Torque Control of Induction Machines," in 12th International Power Electronics and Motion Control Conference, Portoroz, Aug. 2006, pp. 314-319.

[20] A. Accioly, F. Bradaschia, M. Cavalcanti, F. Neves, and V. Lima, "Generalized modulation strategy for matrix converters - part I," 2007. PESC 07. 2007 IEEE 38th Annual Power Electronics Specialists Conference, pp. 646-652, 2007.

[21] F. Bradaschia, M. Cavalcanti, F. Neves, V. Lima, and A. Accioly, "Generalized modulation strategy for matrix converters - part II," 2007. PESC 07. 2007 IEEE 38th Annual Power Electronics Specialists Conference, pp. 665-671, 2007.

[22] P. Cortes, J. Rodriguez, R. Vargas, and U. Ammann, "Cost Functionbased Predictive Control for Power Converters," in IEEE Industrial Electronics, IECON 2006 - 32nd Annual Conference on, Paris, France, Nov. 2006, pp. 2268-2273.

[23] J. Rodriguez, J. Pontt, C. A. Silva, P. Correa, P. Lezana, P. Cortes, and U. Ammann, "Predictive Current Control of a Voltage Source Inverter," IEEE Trans. Ind. Electron., vol. 54, no. 1, pp. 495-503, Feb. 2007.

[24] X. Lin-Shi, F. Morel, A. M. Llor, B. Allard, and J.-M. Rétif, "Implementation of Hybrid Control for Motor Drives," IEEE Trans. Ind. Electron., vol. 54, no. 4, pp. 1946-1952, Aug. 2007.

[25] M. Pacas and J. Weber, "Predictive direct torque control for the PM synchronous machine," IEEE Trans. Ind. Electron., vol. 52, no. 5, pp. 1350-1356, Oct. 2005.

[26] E. Monmasson and M. N. Cirstea, "FPGA Design Methodology for Industrial Control Systems - a Review," IEEE Trans. Ind. Electron., vol. 54, no. 4, pp. 1824-1842, Aug. 2007. 